\title{
Fabrication and characterization of PZT thin film vibrators for micromotors
}

\author{
P. Muralt, M. Kohli, T. Maeder, A. Kholkin, K. Brooks, and N. Setter (1) \\ R. Luthier (2) \\ 1) Laboratoire de Céramique, Swiss Federal Institute of Technology (EPFL), CH-1015 Lausanne, Switzerland. \\ 2) Asulab S.A., Research Laboratory of the SMH group, \\ CH-2074 Marin-Epagnier, Switzerland.
}

Version of record: Sensors and Actuators A 48 (2), 157-165, 1995.

http://hdl.handle.net/10.1016/0924-4247(95)00994-9

\begin{abstract}
For the first time we have characterized a micromotor driven by a piezoelectric $\mathrm{PZT}\left(\mathrm{PbZr}_{\mathrm{x}} \mathrm{Ti}_{1-\mathrm{x}} \mathrm{O}_{3}\right)$ thin film. Sputter and sol-gel techniques have been applied for the deposition of the PZT films onto a silicon stator membrane, which was 20 to $30 \mu \mathrm{m}$ thick and had a diameter of $4 \mathrm{~mm}$. The amplitudes of the membrane deflections have been measured by means of laser interferometry. They are as large as $800 \mathrm{~nm} / \mathrm{V}$ at the first resonance $(26 \mathrm{kHz})$, and $60 \mathrm{~nm} / \mathrm{V}$ at $1 \mathrm{~Hz}$. This is one order of magnitude larger than previously reported for a $\mathrm{ZnO}$ activated device of similar geometry. The operation of the motor was obtained at 1 to $3 \mathrm{~V}_{\text {rms }}$, with speeds of up to $200 \mathrm{rpm}$ at $1.1 \mathrm{~V}_{\mathrm{rms}}$ and torques of $35 \mathrm{nN} \cdot \mathrm{m}$ at $2.5 \mathrm{~V}_{\mathrm{rms}}$ and $1 \mathrm{mN}$ force between rotor and stator. In comparison with the conceptually identical $\mathrm{ZnO}$ version published by Racine et al. this is an improvement by a factor of 3 in speed per volt. Taking into account the linear increase of the torque with the stator vibration frequency, the torque per voltage is a factor two higher. A long time test of $100 \mathrm{~h}$ showed no degradation of the motor performance.
\end{abstract}

Keywords: Micromotors; Piezoelectrics; PZT; Thin-film vibrators

\section{Introduction}

The miniaturization of ultrasonic motors is a subject of keen interest. This type of motor is considered to be superior to other types of micromotors for down scaling: magnetic forces show a less favorable scaling down behavior; and the electrostatic forces do not achieve the high energy densities realized in piezoelectric materials [1]. Such micromotors will allow further miniaturization accompanied by an increase in the functionality of micro robots, autofocusing lens systems, watches and precision positioning devices. The fabrication technology has to be adapted to the small dimensions. The number of costly and often unreliable micro-assembly steps has to be reduced. Cost effective batch processing enabled by thin film technologies and silicon micro machining has to be applied as much as possible. An attractive approach is a so-called hybrid micromotor, where the stator consists of a piezoelectric thin film with its electrodes on a silicon diaphragm obtained by micro machining. The rotor is fabricated by rather classical means and added in an assembly step.

In the past three years the first piezoelectric thin film micromotors of this hybrid type have been demonstrated, either exploiting travelling ultrasonic flexural waves [2-4] or standing flexural waves [5] in the membrane. With regard to bulk material properties, $\mathrm{PbZr}_{\mathrm{x}} \mathrm{Ti}_{1-\mathrm{x}} \mathrm{O}_{3}(\mathrm{PZT})$ appears to be the best choice for the piezoelectric film. However, PZT thin film processing and integration issues complicate device fabrication. The high deposition or annealing temperatures of about $600{ }^{\circ} \mathrm{C}$ are usually not compatible with other materials on the device and inter diffusion and/or delamination may occur [6]. For this reason the first micromotors have either been fabricated with the much less effective piezoelectric $\mathrm{ZnO}$ [2,5], or, when PZT films have been applied, suffered a very fast degradation, preventing a characterization of the motor $[3,4]$. 
In this work we report for the first time on the functional characterization of a PZT thin film actuated micromotor. The motor design is of the type with the piezoelectrically activated standing flexure waves in a silicon membrane. The piezoelectric film, as well as the ground electrode below, cover the whole membrane. The driving voltage is supplied to the top electrode, which has an appropriate pattern to excite the useful mode for motor operation. The coupling between the electric field in the piezoelectric film and the deflection of the membrane is due to the transverse piezoelectric effect, which creates a stress in the piezoelectric film, parallel to the membrane plane, causing the membrane to bend. (This mechanism requires a total membrane thickness which is more than 2 times larger than the PZT film thickness.) The deflections of the membrane are converted into a rotation by a rectifying rotor [7], which has tilted elastic legs (also called fins: "elastic fin motor" [7]). This rectification works in principle as follows (see Fig. 1): When the membrane moves towards the elastic fins, the latter are compressed and bent. In this phase the fins do not slip because of some frictional forces. So the rotor turns in order to release the compression. When the membrane moves away from the fins (decompression) the frictional forces are minimal and the fins glide forward, following the body of the rotor.

The first hybrid version of this motor ("elastic force motor") has been fabricated and characterized by Racine et al. [5] with $\mathrm{ZnO}$ films. In our work we applied identical rotors (as used by Racine et al.) in order to compare our PZT version with the published $\mathrm{ZnO}$ version. According to bulk ceramic values of piezoelectric coefficients one would expect an improvement of about 6 times in the performance i.e. a higher torque, a higher speed or a lower voltage, depending on the design. Especially interesting is the lowering of the driving voltage. Compatibility with standard IC's and battery cells would require a peak to peak voltage of $6 \mathrm{~V}$ or less. The existing $\mathrm{ZnO}$ motors need at least $20 \mathrm{~V}_{\mathrm{pp}}$ [5]. There is therefore a need to have a material that lowers the driving voltage by a factor of three or more.

\section{Experimental}

The structure of the piezoelectric thin film stator was made as simple as possible. The sequence of thin films can be seen in Fig. 2. The electrode below the PZT film (bottom electrode of Pt/Ta) was not structured. Contact pads, conductor lines and top electrodes were patterned from the same aluminum film, deposited directly on the PZT layer. The additional capacity of the contact pads and the conductor lines amounts to $18 \%$ of the total capacity and was not considered to be important for the present investigation.

The stator was micro machined out of a 3" silicon wafer. The wafers have been purchased with thermal oxide and LPCVD-Si ${ }_{3} \mathrm{~N}_{4}$ layers. Their thicknesses have been matched for a small and slightly tensile resulting stress and serve as a mask for the silicon micro machining (etching in $\mathrm{KOH}$ ), and as a barrier layer against lead-silicon inter diffusion. The first processing step was the structuring of these two layers on the back side of the wafer for the later $\mathrm{KOH}$ etching. Next the bottom electrode $(100 \mathrm{~nm} \mathrm{Pt} / \mathrm{Ta})$ was sputter deposited on the front side. The selection of the right electrode material and process is crucial. We tested several adhesion layers between $\mathrm{Si}_{3} \mathrm{~N}_{4}$ and $\mathrm{Pt}$. Among $\mathrm{Ti}, \mathrm{TiO}_{2} / \mathrm{Ti}, \mathrm{Ta}, \mathrm{Ta}_{2} \mathrm{O}_{5} / \mathrm{Ta}$ the single $\mathrm{Ta}$ layer withstood best the annealing in oxygen at $600{ }^{\circ} \mathrm{C}$ and the subsequent patterning steps. This is in contrast to the optimal solution on the barrier layer $\mathrm{SiO}_{2}$, where the $\mathrm{TiO}_{2} / \mathrm{Ti}$ is by far the best choice [6] among the above mentioned materials.

For the PZT deposition two methods have been applied: sol gel and sputtering. The processes needed maximal temperatures of $600^{\circ} \mathrm{C}$ (sol gel) and $550^{\circ} \mathrm{C}$ (sputtering). The sol gel process used the organometallic precursors $\mathrm{Pb}\left(\mathrm{C}_{2} \mathrm{H}_{4} \mathrm{O}_{2}\right)_{2} \cdot 3 \mathrm{H}_{2} \mathrm{O}, \mathrm{Zr}\left(\mathrm{OCH}_{2} \mathrm{CH}_{2} \mathrm{CH}_{3}\right)_{4}$ and $\mathrm{Ti}\left[\mathrm{OCH}\left(\mathrm{CH}_{3}\right)_{2}\right]_{4}$. The film exhibits a strong $<111>$ texture. Details have been previously reported [8,9]. The sputtered PZT with $<100>$ orientation was grown in situ from 3 simultaneously operating magnetrons with metal targets. The orientation was obtained due to a $<100>$ oriented lead titanate template layer of $30 \mathrm{~nm}$ thickness, which was deposited previously in the same sequence. A detailed description of the process is given in ref. [10]. In both cases the PZT film was $0.6 \mu \mathrm{m}$ thick, which was enough for the low voltage operation we aimed at. 


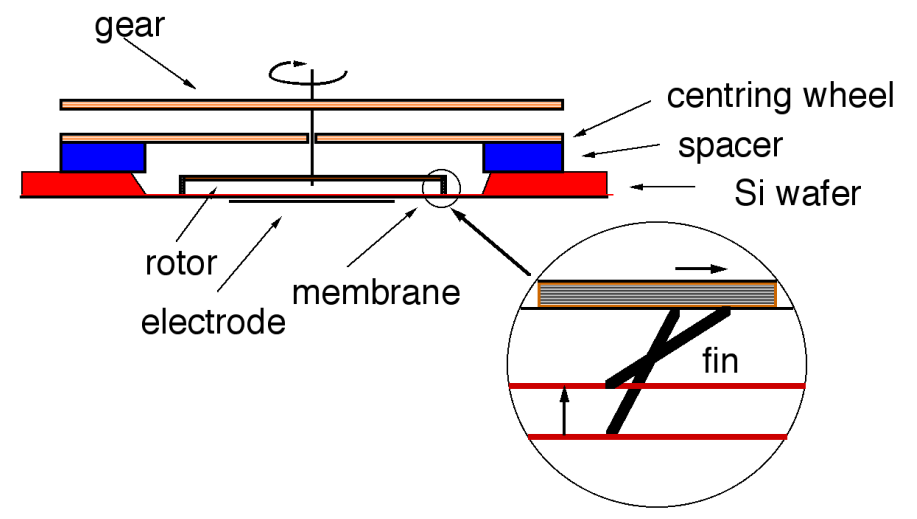

Figure 1. Schematic cut through the motor. The fins are tilted out of the drawing plane.

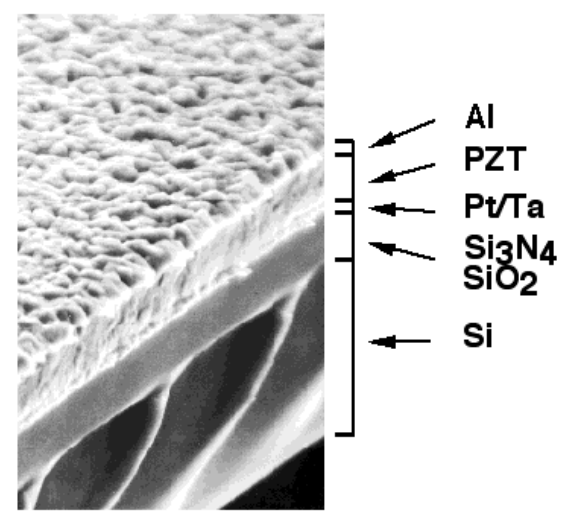

Figure 2. Image of a cut through a membrane as obtained by scanning electron microscopy.

The aluminum top electrode was deposited by evaporation and structured afterwards. Finally the silicon etching in $\mathrm{KOH}$ of the back side was performed, leaving membranes with 10 to $30 \mu \mathrm{m}$ thick silicon, depending on the etching time. Figure 2 shows a cross section through a cleaved membrane, as observed by SEM (scanning electron microscopy). 10 membranes were simultaneously etched on the same quarter wafer. For motor operation the wafer was turned up-side down. The rotor was thus moving on the silicon side in the etched cavity (see Fig. 1).

The circular stator membranes had diameters of $4 \mathrm{~mm}$. The top electrode with a diameter of $2 \mathrm{~mm}$ in the center of the membrane was designed for the ground mode $\mathrm{B}_{00}$. The same geometry was also applied to excite the $\mathrm{B}_{10}$ mode with one circular node. The $3.5 \mathrm{~mm}$ diameter rotor was cut out by laser from a metallic foil. The desired tilt angle of the legs was achieved by molding in a pressing machine. A steel axle of 0.25 $\mathrm{mm}$ diameter is clamped into the rotor and centered by a centering wheel resting on spacers. On the top of the axle a wheel was fixed which serves as a load to increase the friction and the moment of inertia for torque measurements.

The speed measurements have been performed either by measuring the time for 20 turns or by analyzing the rotation angles $\phi$ by means of a video. The latter method was also applied to determine the torque $\mathrm{M}$ during the acceleration of the wheels from zero to maximum speed:

$$
M=I \cdot \dot{\Omega}, \quad \Omega=\frac{d \phi}{d t}
$$

The moment of inertia $I$ and the force $F$ between rotor and stator were varied with the help of tiny balls placed on top of the load wheel.

\section{Results}

\subsection{PZT thin films}

The dielectric constant and the dielectric losses have been measured by means of an impedance analyzer (HP 4191). The results are summarized in Table 1. The sol-gel film shows a much higher dielectric constant than the sputtered film. We believe that this is mainly due to a non optimized composition of the $\mathrm{Zr}$ to $\mathrm{Ti}$ ratio in the sputtered film. The losses, tand, obtained with directly contacted small electrode spots $(0.6 \mathrm{~mm}$ diameter) on test wafers undergoing no etching steps, yielded values of 3 to $4 \%$ in the frequency range from $100 \mathrm{~Hz}$ to $100 \mathrm{kHz}$. In case of the much larger electrodes on the membranes, the losses from the series resistivities of the conductor lines become dominant above $1 \mathrm{kHz}$. The values at $100 \mathrm{~Hz}$ are, however, comparable to the values obtained with small spots. The yield of the sputtered PZT films is quite high: 
From 10 membranes measured, only one had a too high loss, whereas the others fell within a narrow range around $4 \%$. This indicates that we have no problem with pinholes arising from the deposition processes, nor is the quality degraded during the etching steps. After a long time test of $100 \mathrm{~h}$ motor operation we have seen no degradation of the thin films. At the end the rotor was turning at the same speed as at the beginning.

\subsection{Membranes}

The deflections of the membranes have been analyzed by means of a laser Michelson interferometer. The signals were collected and treated with the help of a HP3562A dynamic signal analyzer. The frequency response of the membranes in the range of 0 to $100 \mathrm{kHz}$ is shown in Figs 3 and 4. Four resonances were observed. The strongest one is the fundamental mode, when the displacement measurement is made in the center of the membrane. The symmetry of the resonance's was observed by placing quartz powder on the membrane. The quartz particles move away from the regions with high amplitudes, thus mapping the nodal lines. With increasing frequency the $\mathrm{B}_{00}, \mathrm{~B}_{01}, \mathrm{~B}_{02}$ and $\mathrm{B}_{10}$ modes were observed. An image for the latter is shown in Fig. 5. The diameter of the nodal circle $\left(B_{10}\right)$ was $1.7 \mathrm{~mm}$. The top electrode $(=2 \mathrm{~mm})$ is therefore $0.3 \mathrm{~mm}$ too large for an optimal excitation of $\mathrm{B}_{10}$. For the thickness measurements some of the membranes have been broken and analyzed in an optical microscope. The results are summarized in Table 2. It should be noted that the response of the membrane with the sputtered PZT has been measured off-center. Since the $\mathrm{B}_{01}$ and $\mathrm{B}_{02}$ nodal lines traverse the center of the membrane, a measurement at this position would yield larger amplitudes of $\mathrm{B}_{00}$ and $\mathrm{B}_{10}$ and vanishing amplitudes of the $\mathrm{B}_{01}$ and $\mathrm{B}_{02}$ modes. The question remains as to why the latter two modes are observed at all, since the excitation of the membrane was intended to be a radial one. However, there is a violation of the circular geometry in the design of the electrodes. The top electrode in the center is connected with two stripes in opposite directions to the contact pads. The straight line defined by these two stripes is identical to one of the nodal lines of $\mathrm{B}_{02}$. Other origins are imperfections of the fabrication. The PZT films are not perfectly homogeneous. Especially the sputtered PZT film is quite inhomogeneous at the outer zone of the wafer. Inside the membrane the thickness varies as $+/-5 \%$. The sol gel film is much better $(<+/-1 \%$ inside a membrane). In addition the silicon micro machining of circular holes is not trivial. Deviations from a perfect circle occur due to the very anisotropic etching.

The amplitudes of these resonances are by far larger than the ones previously obtained with $\mathrm{ZnO}$ on similar membranes [11]. The relatively high amplitude at zero frequency (see Figs 3 and 4, Table 4) is also a big improvement. The quality factors have to be interpreted cautiously. Acoustical emission into the substrate and into the air are probably the strongest dissipation mechanisms.

Table 1. The measured dielectric parameters of the PZT thin films.

\begin{tabular}{|l|c|c|}
\hline & sol gel PZT & sputtered PZT \\
\hline $\begin{array}{l}\text { dielectric constant } \\
(100 \mathrm{~Hz})\end{array}$ & 950 & 610 \\
\hline $\begin{array}{l}\text { dielectric loss } \\
(100 \mathrm{~Hz})\end{array}$ & $3 \%$ & $\begin{array}{c}3.5 \text { to } 4.5 \% \\
\text { (9 from } 10 \text { membranes) }\end{array}$ \\
\hline
\end{tabular}


Table 2. Frequencies and amplitudes of the resonances, as derived from Figs 3 (no bias) and 4.

\begin{tabular}{|c|c|c|c|c|c|c|}
\hline & \multicolumn{3}{|c|}{ sol gel PZT, $0.6 \mu \mathrm{m}$} & \multicolumn{3}{|c|}{ sputtered PZT, $0.6 \mu \mathrm{m}$} \\
\hline $\begin{array}{l}\text { membrane } \\
\text { thickness: }\end{array}$ & \multicolumn{3}{|c|}{$\begin{array}{c}0.85 \mu \mathrm{m} \mathrm{Si}_{3} \mathrm{~N}_{4}+\mathrm{SiO}_{2} / \\
27 \mu \mathrm{m} \mathrm{Si}\end{array}$} & \multicolumn{3}{|c|}{$\begin{array}{c}0.85 \mu \mathrm{m} \mathrm{Si}_{3} \mathrm{~N}_{4}+\mathrm{SiO}_{2} / \\
20.5 \mu \mathrm{m} \mathrm{Si}\end{array}$} \\
\hline mode & $\begin{array}{l}\text { freq. } \\
(\mathrm{kHz})\end{array}$ & $\begin{array}{l}\text { Ampl. } \\
(\mathrm{nm} / \mathrm{V})\end{array}$ & $\begin{array}{c}\mathrm{Q} \\
\text { factor }\end{array}$ & $\begin{array}{l}\text { freq. } \\
(\mathrm{kHz})\end{array}$ & $\begin{array}{l}\text { Ampl. } \\
(\mathrm{nm} / \mathrm{V})\end{array}$ & $\begin{array}{c}\mathrm{Q} \\
\text { factor }\end{array}$ \\
\hline $\mathrm{B}_{00}$ & 25.1 & 600 & 39 & 17.7 & 380 & 33 \\
\hline $\mathrm{B}_{01}$ & 53.0 & 20 & & 38.0 & 580 & 34 \\
\hline $\mathrm{B}_{02}$ & 84.5 & 50 & & 58.7 & 180 & 180 \\
\hline$\overline{\mathrm{B}_{10}}$ & 94.3 & 260 & 73 & 71.7 & 140 & 57 \\
\hline
\end{tabular}

Table 3. Summary of the motor performance for two different forces $F$ and moments of inertia $I$. No load: $F=2.4 \times 10^{-4} \mathrm{~N}, I=1.4 \times 10^{-10} \mathrm{~kg} \cdot \mathrm{m}^{2}$. Load with 5 tiny balls: $F=9.8 \times 10^{-4} \mathrm{~N}, I=4.6 \times 10^{-10} \mathrm{~kg} \cdot \mathrm{m}^{2}$. The maximum torque at zero speed is given.

\begin{tabular}{|l|c|c|c|c|c|}
\hline & $\begin{array}{c}\text { Sol-gel } \\
\text { no bias } \\
94 \mathrm{kHz} \\
\mathrm{B}_{10}\end{array}$ & $\begin{array}{c}\text { Sol-gel } \\
+2 \mathrm{~V} \\
94 \mathrm{kHz} \\
\mathrm{B}_{10}\end{array}$ & $\begin{array}{c}\text { Sputter } \\
-2 \text { Vbias } \\
21 \mathrm{kHz} \\
\mathrm{B}_{00}\end{array}$ & $\begin{array}{c}\text { Sputter } \\
\text { no bias } \\
78 \mathrm{kHz} \\
\mathrm{B}_{10}\end{array}$ & $\begin{array}{c}\text { Sputter } \\
-2 \mathrm{~V} \\
78 \mathrm{kHz} \\
\mathrm{B}_{10}\end{array}$ \\
\hline $\begin{array}{l}\text { Speed per ac voltage } \\
F=2.4 \times 10^{-4} \mathrm{~N} \\
\left(\mathrm{rpm} / \mathrm{V}_{\text {rms }}\right)\end{array}$ & 140 & 180 & 32 & 80 & 100 \\
\hline $\begin{array}{l}\text { Torque per ac voltage } \\
\begin{array}{l}F=2.4 \times 10^{-4} \mathrm{~N} \\
\left(\mathrm{nN} \cdot \mathrm{m} / \mathrm{V}_{\text {rms }}\right)\end{array}\end{array}$ & 4.3 & & 1.8 & & 3.9 \\
\hline $\begin{array}{l}\text { Torque per ac voltage } \\
F=9.8 \times 10^{-4} \mathrm{~N} \\
\left(\mathrm{nN} \cdot \mathrm{m} / \mathrm{V}_{\text {rms }}\right)\end{array}$ & 12 & 3.2 & & 11 \\
\hline
\end{tabular}

Table 4: Approximate piezoelectric coefficients $e_{31}$, as calculated from the quasi static deflections of membranes according to eqn. 7 .

\begin{tabular}{|l|c|c|}
\hline & $\begin{array}{c}\text { Deflection near } f=0 \\
(\mathrm{~nm} / \mathrm{V})\end{array}$ & $\begin{array}{c}e_{31} \text { calculated } \\
\left(\mathrm{C} / \mathrm{m}^{2}\right)\end{array}$ \\
\hline Sputtered film, no bias & 60 & -0.40 \\
\hline Sol gel film, no bias & 38 & -0.44 \\
\hline Sol gel film, +2 V bias & 55 & -0.63 \\
\hline
\end{tabular}




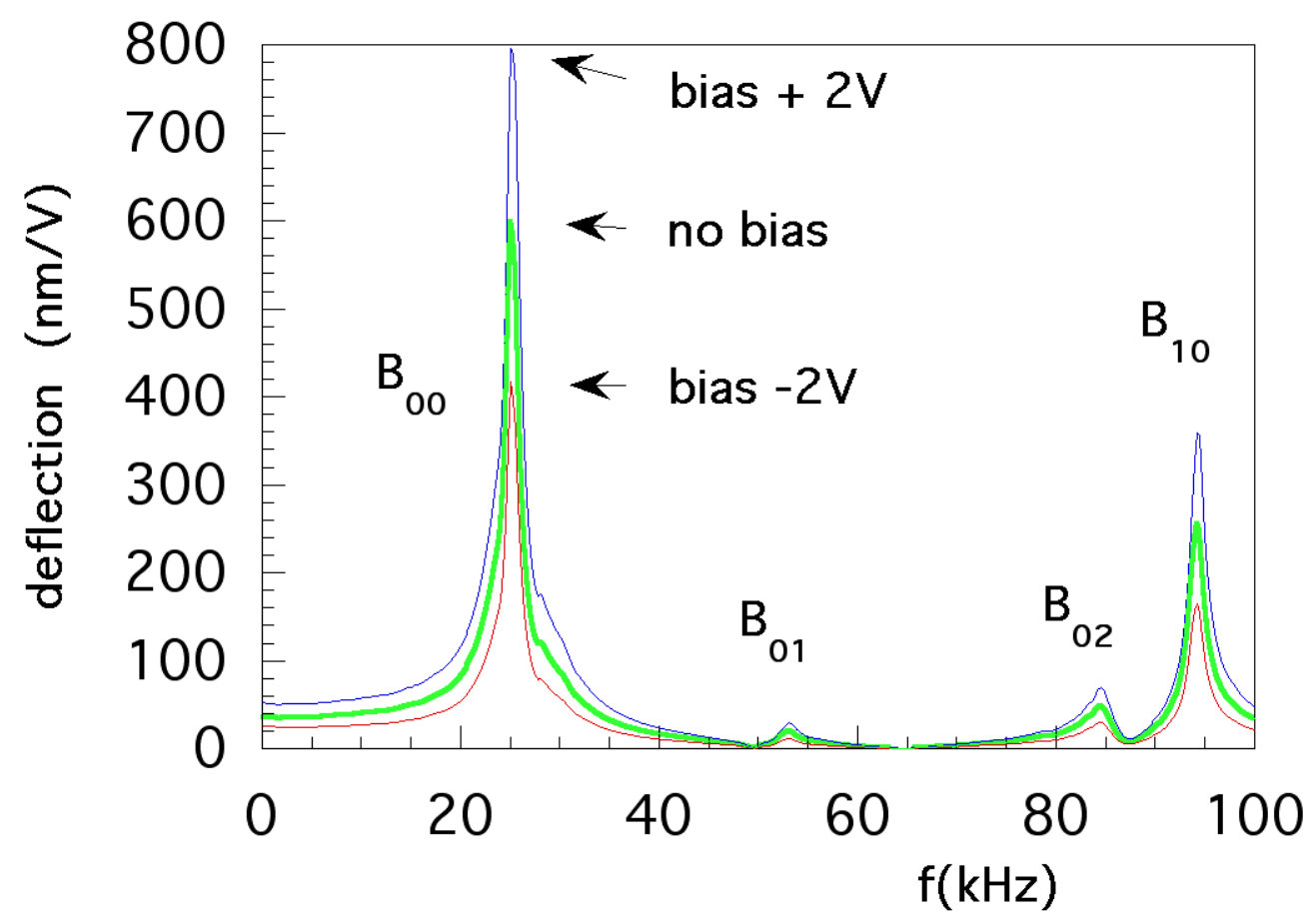

Figure 3. The deflection of a membrane, as measured by means of laser interferometry as a function of the frequency of the ac excitation of $50 \mathrm{mV}$. The membrane has a diameter of $4 \mathrm{~mm}$, covered with the sol gel PZT film. The different curves show the effect of a de bias added to the ac voltage (sign of top electrode).

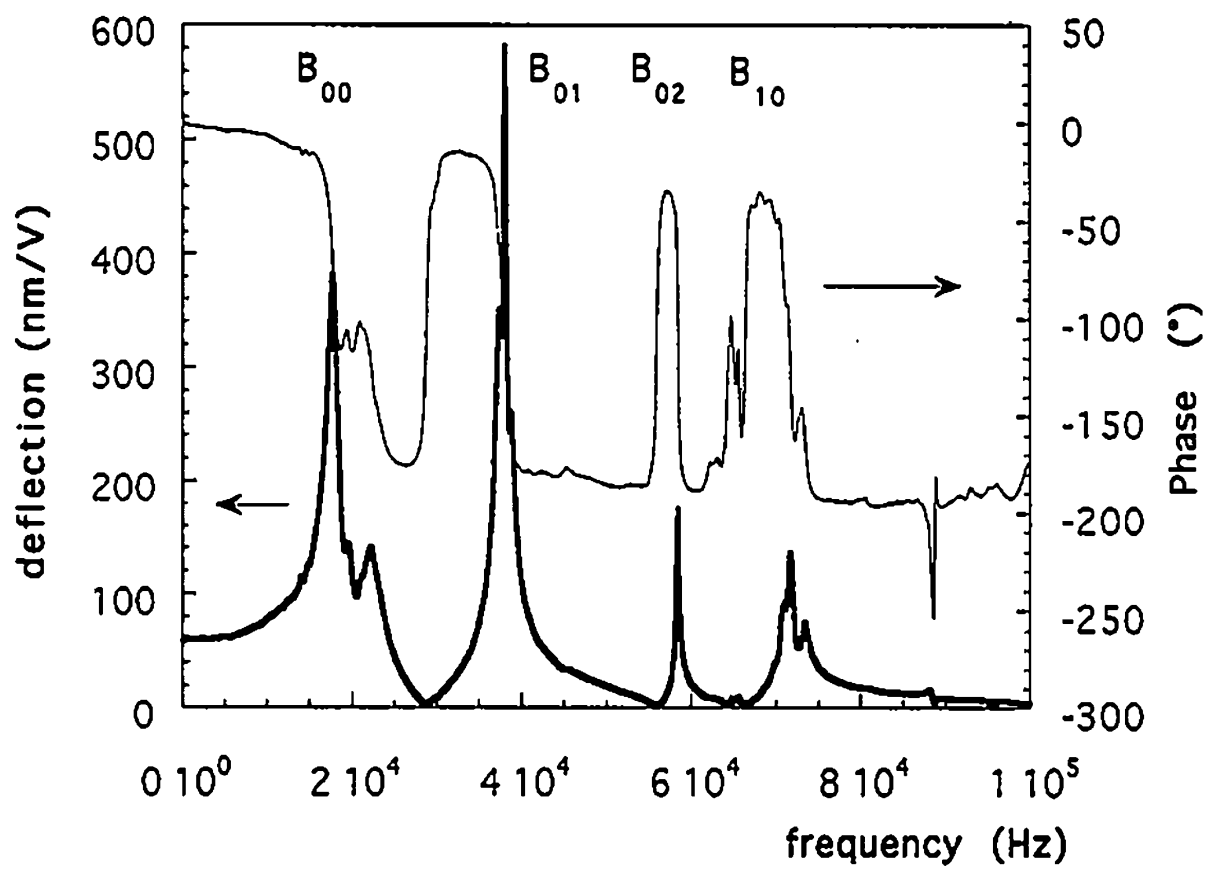

Figure 4: The deflection of a membrane, as measured by means of laser interferometry as a function of the frequency of the ac excitation of $50 \mathrm{mV}$. The membrane has a diameter of $4 \mathrm{~mm}$, covered with the sputter deposited PZT film. 


\subsection{Motor operation}

The motor was operated at the membrane resonances. The results are summarized in Table 3. On some of the membranes it ran also with the $\mathrm{B}_{02}$ mode. The resonance frequencies shifted to higher values with the rotor on the membrane. The motor speed was measured as a function of applied ac and dc voltages (Fig. 6). The threshold voltage needed to cause the motor to turn was $2.5 \mathrm{~V}_{\mathrm{pp}}\left(0.9 \mathrm{~V}_{\mathrm{rms}}\right)$ at $0 \mathrm{~V}$ bias, and $2 \mathrm{~V}_{\mathrm{pp}}$ $\left(0.7 \mathrm{~V}_{\mathrm{rms}}\right)$ at $2 \mathrm{~V}$ bias. The motor does not work at arbitrarily low speeds. The minimal speed observed was $20 \mathrm{rpm}$ with a force of $2.4 \times 10^{-4} \mathrm{~N}$ and $6 \mathrm{rpm}$ with a force of $9.8 \times 10^{-4} \mathrm{~N}$. In the voltage range investigated no saturation of the speed was observed. A dc bias was added to ac voltage (top electrode). The sol-gel film required a positive biasing and the sputtered film a negative biasing in order to enhance the speed, in accordance with the membrane deflection measurements (see Fig. 3). The films are "self-polarized" either by the stresses in the PZT films or by the deposition processes. The measurements of the torque were very sensitive to misalignments of the axle and the wheels. Also the positioning on the membrane played a crucial role. A more perfect mounting of the motor therefore may still increase the obtained values. Two plots of the speed $\Omega$ vs. the time $t$ are given in Fig. 7, where the dotted lines are the curve fits to the angular speed $\Omega(t)$ according to:

$$
\Omega(t)=\Omega_{\infty}\left(1-e^{-t / \tau}\right), \quad \tau=\frac{I \cdot \Omega_{\infty}}{M_{0}} ;
$$

and the solid lines the acceleration curve according to:

$$
\dot{\Omega}(t)=\frac{\Omega_{\infty}-\Omega(t)}{\tau}=\frac{\Omega_{\infty}}{\tau} e^{-t / \tau} .
$$

The torque at zero speed $M_{0}$ as a function of the applied voltage is shown in Fig. 8.

\section{Discussion}

\subsection{Membranes}

Theoretical values of the resonance frequencies of the radial modes $B_{k 0}$ can be found in textbooks [12]. The formula is valid for thin circular disks clamped at the border.

$$
\omega_{k}=\lambda_{\kappa}^{2} \cdot \frac{h}{a^{2}} \cdot \sqrt{\frac{Y}{12\left(1-v^{2}\right) \rho}}
$$

where $h$ and $a$ are the thickness and the radius of the membrane, $Y$ is the Young's modulus, $v$ the Poisson's ratio and $\rho$ the density. The coefficients $\lambda_{0}$ and $\lambda_{1}$ amount to 3.190 and 6.306 respectively. The amplitude A as a function of the radius $r$ can be calculated analytically [12]:

$$
A(r)=c_{1} \cdot J_{0}\left(\lambda_{k} \cdot \frac{r}{a}\right)+c_{2} \cdot J_{0}\left(i \cdot \lambda_{k} \cdot \frac{r}{a}\right),
$$

where $J_{0}$ are the Bessel functions of order $0 . c_{2} / c_{1}$ amounts to 0.056 and -0.025 for $\mathrm{B}_{00}$ and $\mathrm{B}_{10}$ respectively. The results of the calculations are displayed in Fig. 9. The radius of the nodal circle of $\mathrm{B}_{10}$ was measured as $(0.38+/-0.1) \cdot a$, which is in excellent agreement with the theoretical value obtained from eqn. 4 . 

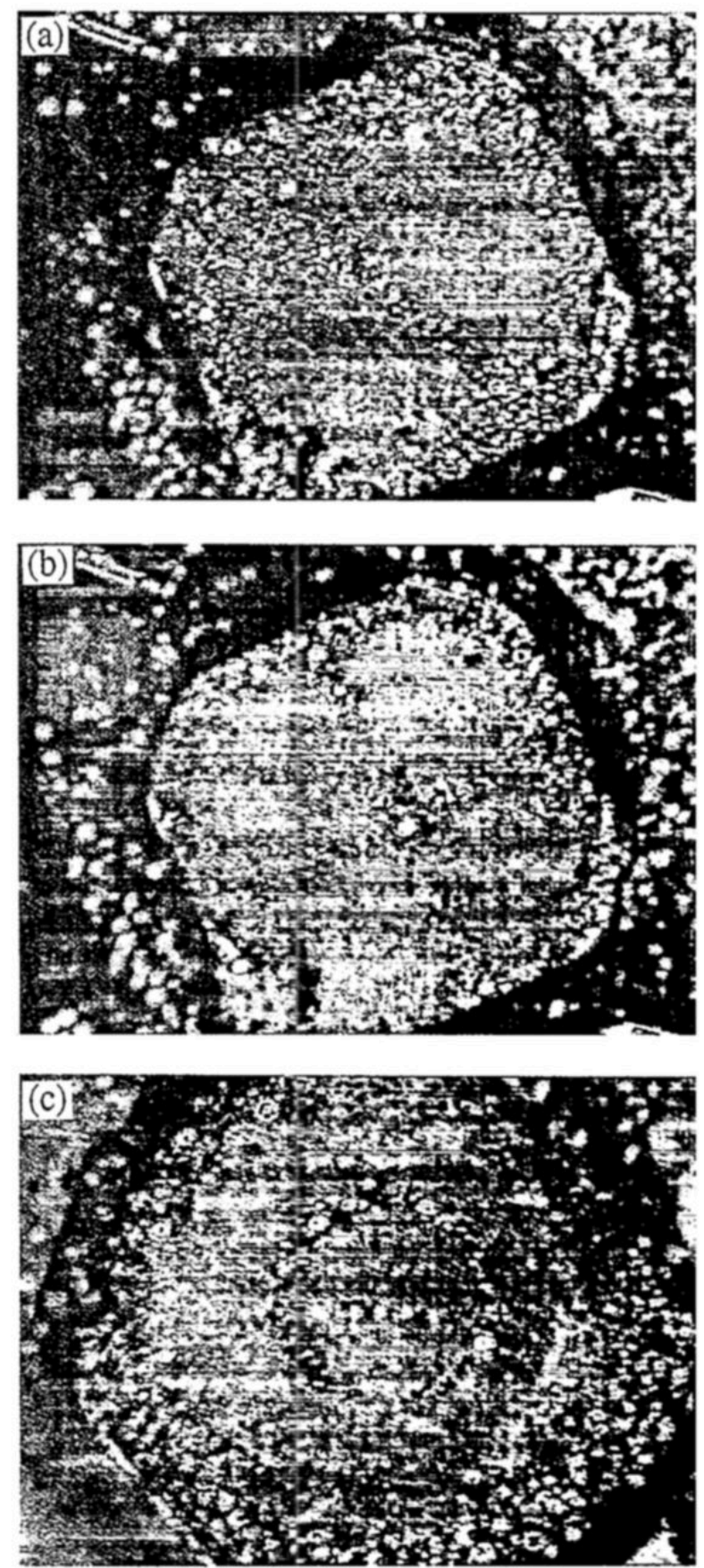

Figure 5. Picture of nodal lines created by quartz powder on a resonating membrane. $B_{01}$ and $B_{02}$ : sputtered PZT film, $B_{10}$ : sol gel PZT film.

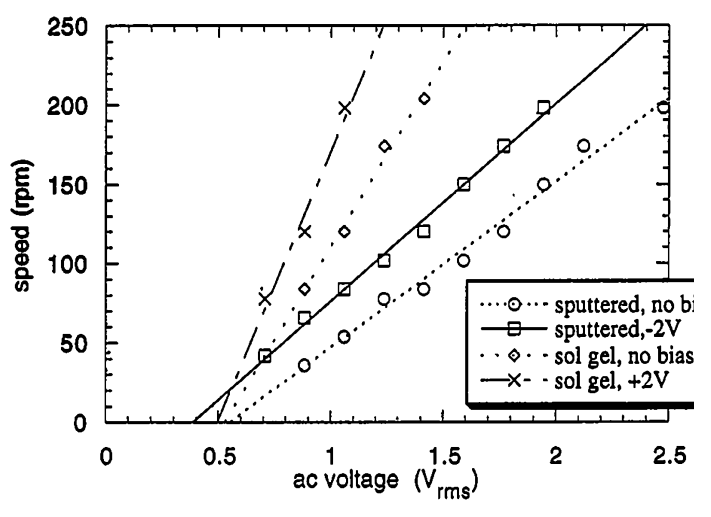

Figure 6. The speed as a function of the ac voltage for both types of membranes resonating in the $B_{10}$ mode, with and without de bias.
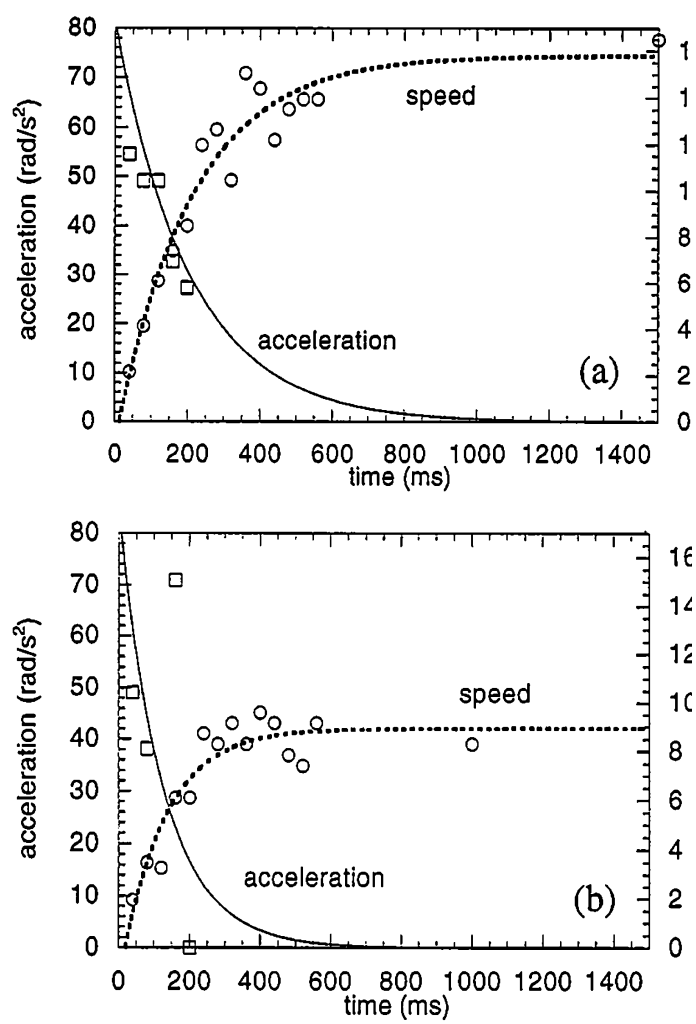

Figure 7. Speed and acceleration vs. time for two different forces. The curve fits are calculated according to eqns. 2 and 3. Experimental conditions: sputter deposited PZT film, $B_{10}$ mode, $78 \mathrm{kHz}, 2.5 \mathrm{~V}_{\text {rms }},-2 \mathrm{~V}$ dc bias; (a) $F=2.4 \times 10^{-4} \mathrm{~N}$, b) $F=$ $9.8 \times 10^{-4} \mathrm{~N}$. 


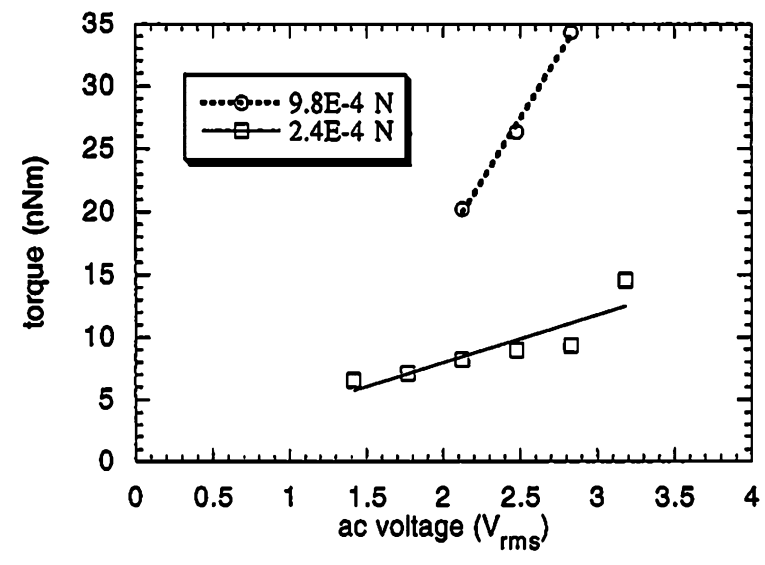

Figure 8. Measured motor torque vs. voltage for two different forces. Experimental conditions: sputtered deposited PZT film, $B_{10}$ mode, $78 \mathrm{kHz},-2 \mathrm{~V}$ dc bias.

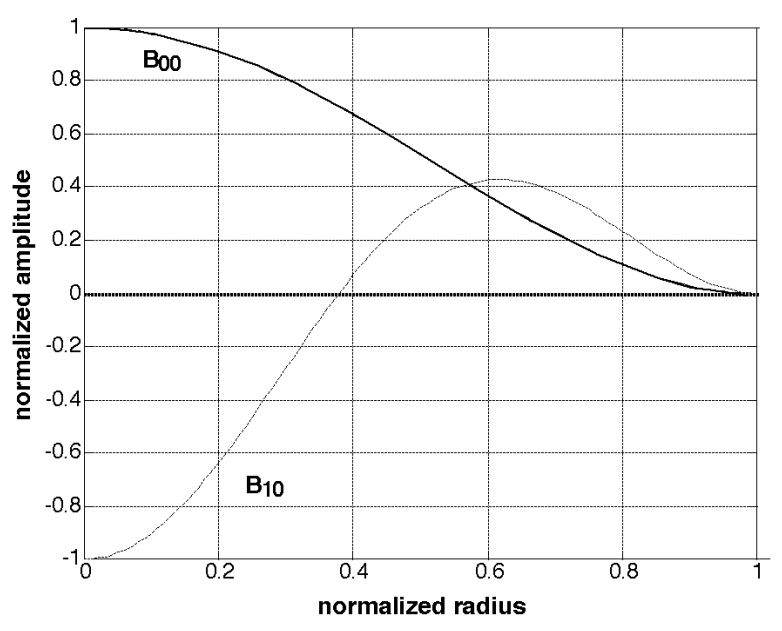

Figure 9. Calculated shape of the membrane deflection at resonance. The insert shows the position of the rotor fins.

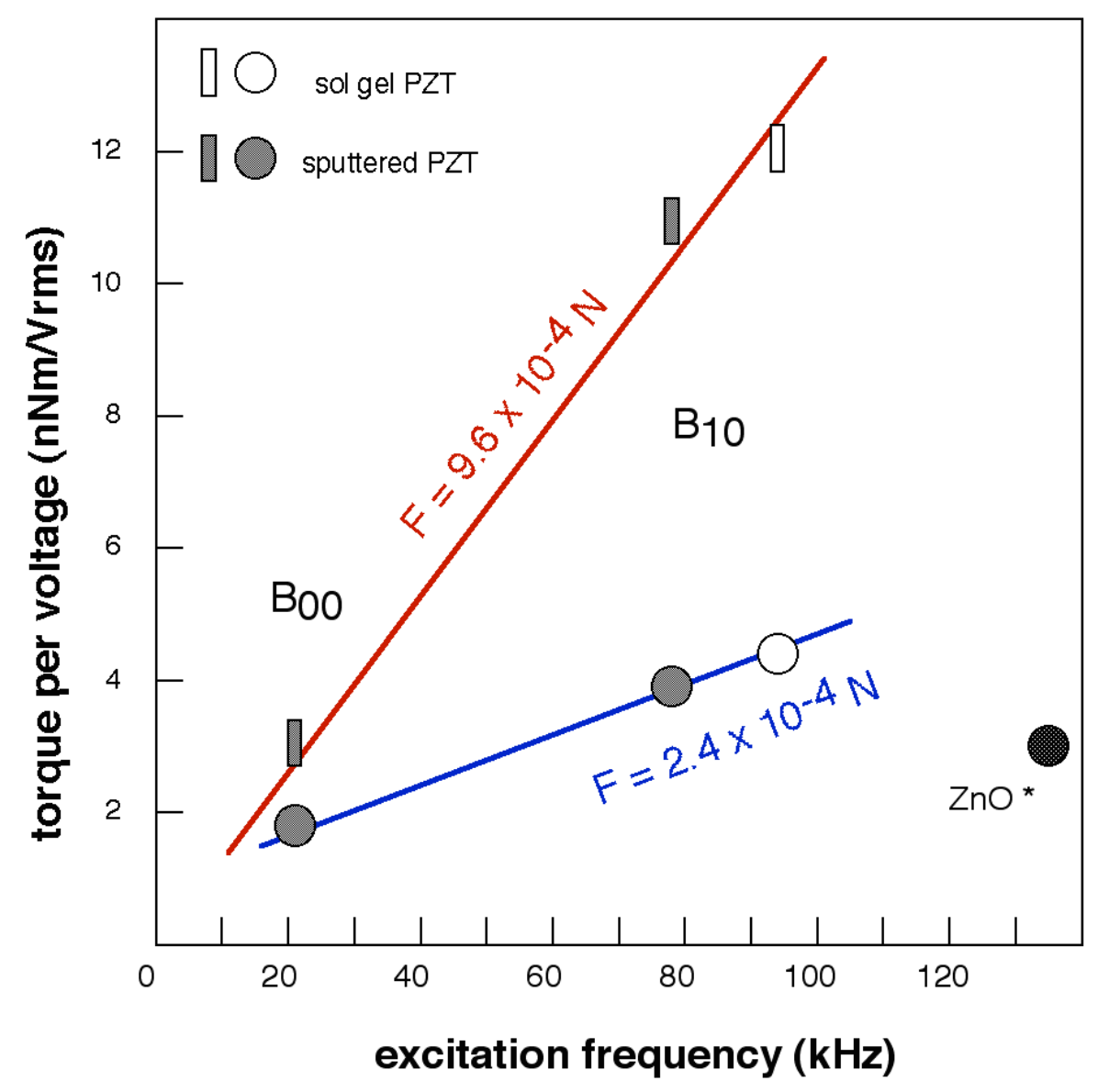

Figure 10. The motor torque per applied ac voltage for different materials, forces and modes vs. the excitation frequency. The $\mathrm{ZnO}$ data are from ref. [5]. 
The resonant frequencies of $\mathrm{B}_{00}$ and $\mathrm{B}_{01}$ fit well to the formula (eqn. 3), indicating low residual stresses in the membranes. This means that the stresses in the films are low, since the silicon membrane, being part of the monocrystalline substrate, should have no stress. The presence of film stresses results in a shift of the ratio of the eigenfrequencies $f\left(\mathrm{~B}_{10}\right) / f\left(\mathrm{~B}_{00}\right)$. The pure thin disc model predicts a value of 3.91 [12]. Our membranes show a ratio of 3.76 and 4.05 for the sol-gel and the sputtered samples respectively. These ratios depart within $\pm 4 \%$ from the predicted value. These are in fact small shifts and might be within the errors of the membrane geometry, such as uniformity of the membrane thickness. In case of the sol-gel sample, where we have less perturbed spectral line shapes (see Fig. 3) the shift might be explained by a tensile stress of the ensemble of the thin films of about $100 \mathrm{MPa}$, as obtained by a first order perturbation calculation.

Below the first resonance the deflection of the membrane is quasi static. From the values near $f=0$ one can approximately derive the piezoelectric constant $d_{31}$ or rather $e_{31}=d_{31} / s^{\mathrm{E}}{ }_{11}$, where $s^{\mathrm{E}}{ }_{11}$ is the elastic compliance. It must be assumed, however, that there is not too much tensile stress in the piezoelectric film, otherwise the forces stretching the membrane are too strong. It is assumed that the membrane bows approximately as under a homogeneous pressure. For that situation the deflection function $u(r)$ is given by [12]:

$$
u(r)=\frac{A}{a^{4}}\left(r^{2}-a^{2}\right)^{2}
$$

where $A$ is the amplitude of the deflection in the center of the membrane, $a$ is the radius of the membrane. The sum of the radial moments with respect to the central plane of the membrane has to vanish, i.e.

$$
M_{r}=\int_{-h / 2}^{h / 2} \sigma_{r, m} \cdot z \cdot d z+\frac{h}{2} \quad \sigma_{r, p} \cdot t_{p}=0 \quad \sigma_{r, p}=e_{31} \cdot E_{3}
$$

where $h$ denotes the thickness of the membrane, $t_{\mathrm{p}}$ the thickness of the piezoelectric film, $\sigma_{\mathrm{r}, \mathrm{m}}$ the stress in the membrane caused by the bowing, and $E_{3}$ the field applied to the piezoelectric film. Applying this equation to the center of the electrode $(r=0)$ one arrives at:

$$
\frac{Y \cdot h^{2} \cdot A}{3(1-v) \cdot a^{2} \cdot V_{3}} \text { with } V_{3}=E_{3} \cdot t_{p}
$$

The values of the calculated $e_{31}$ are given in Table 4 . They are between $20 \%$ and $30 \%$ of the bulk ceramic value of $2.0 \mathrm{C} / \mathrm{m}^{2}$. These values are quite reasonable and compare well with the piezoelectric coefficient $d_{33}$, measured by interferometry at films on plane wafers, as described in Ref. [13]. The values obtained for the sol-gel film are probably somewhat too small, because of a higher tensile stress of the membrane (see discussion of the eigenfrequencies above).

The recently published piezoelectric constants of thin films are indeed lower than the ones of the bulk ceramics. In most of the films the constants at zero bias field $\left(d_{33}=70 \mathrm{pm} / \mathrm{V}\right.$ [14]) are only about a third of the poled bulk ceramic values. In contrast to bulk ceramic there is also a large difference between zero field and saturation field values $\left(d_{33}=150 \mathrm{pm} / \mathrm{V}\right.$ in saturation [14]). Hence a dc field parallel to the polarization of the film superimposed on the ac field enhances the piezoelectric coupling constant, as demonstrated in Fig. 3.

\subsection{Motor operation}

In comparison to the $\mathrm{ZnO}$ stator (operation at 6 to $10 \mathrm{~V}_{\mathrm{rms}}$ [5]) the PZT stator needs 3 times less voltage to run at equal speeds (operation at 1 to $3 \mathrm{~V}_{\text {rms }}$ ) and a lower starting voltage. The measured torques per applied voltage are, however, only slightly higher, when compared to the data for the unloaded motor from ref. 5 (see Fig. 10).

This discrepancy can be explained by the different driving frequencies. For frequencies lower than the resonance frequency of a single fin one might expect that the torque is proportional to the number of 
compression periods per time, thus proportional to the excitation frequency. Figure 10 suggests indeed such a behavior. The $\mathrm{ZnO}$ motor was run at $134 \mathrm{kHz}$, our PZT motors at $95 \mathrm{kHz}$ (sol-gel) and $78 \mathrm{kHz}$ (sputtered). Corrected for the frequency, the PZT stator would have twice as high a torque as the $\mathrm{ZnO}$ stator per applied ac voltage.

Unfortunately there are no simulation calculations elucidating the mechanisms of the force and impulse transfer from the vibrating stator to the rotor. There is only a study on the frequency behavior [15], in which the relation between the velocity of the vibrating stator $v_{\mathrm{S}}$ to the tangential velocity $v_{\mathrm{R}}$ of the rotor are investigated. For not too high velocities, where the speed saturates, the authors of ref. 15 found:

$$
v_{R}=\alpha \cdot\left(v_{S}-v_{S 0}\right), \quad \text { for } \quad v_{S} \geq v_{S 0}
$$

$v_{\mathrm{S} 0}$ is a minimal velocity required to compress the fins (not only lifting up the rotor) and to overcome the stator surface roughness. The factor $\alpha$ was obtained in the range from 0.75 to 1.4 for the same inclination of the fins as in our case. With the help of eqn. 8 one can calculate an approximate amplitude of the stator vibration below the fins, assuming $\alpha=1$. Without the presence of the rotor this amplitude can be written as $A=A_{0} \cdot \sin (\omega \cdot t)$ and the velocity as $v_{\mathrm{S}}=\omega \cdot A_{0} \cdot \cos (\omega \cdot t)$. In presence of the rotor the amplitude will be reduced and some effective value $A_{\text {eff }}$ is relevant for the speed:

$$
v_{R}=2 \cdot \pi \cdot R \cdot f_{R}=\left(A_{e f f}-A_{e f f, o}\right) \cdot \omega
$$

$R$ is the radius of the fin positions and $f_{\mathrm{R}}$ the speed of the rotor. $A_{\text {eff }, 0}$ is the threshold amplitude related to $v_{\mathrm{S} 0}$.

It is interesting to compare the so obtained amplitudes with the amplitudes of the free membrane, as measured by means of optical interferometry. Since the latter were measured in or near the center of the membrane, the amplitude at the radius of the fin positions was calculated with the help of the amplitude function $A(r)$ of eqn. 4 (see Fig. 9). The relative amplitudes at the radius of the fin positions is 0.15 and 0.29 for $\mathrm{B}_{00}$ and $\mathrm{B}_{10}$ respectively. The results are summarized in Table 5. Except for one experiment (bad mounting of rotor?), the effective amplitude is between 35 and $45 \%$ of the maximal possible amplitude derived from the deflection measurements. The threshold amplitude is around $10 \mathrm{~nm}$. It depends probably a lot on the details of the mounting of the rotor and the roughness of the membrane. One experiment indicates that the motor is faster with a higher threshold amplitude, probably caused by a rougher surface of the stator. The comparison with the $\mathrm{ZnO}$ stator confirms that the PZT stator needs 4 to 10 times less voltage for the same amplitudes. It remains to be clarified why the higher amplitudes do not lead to a higher torque.

\section{Conclusions}

We have shown that the integration of sol gel and sputter deposited PZT films onto membrane structures can be done with a high yield, high dielectric constants, low dielectric losses, and low resulting film stresses. The dc deflections and the amplitudes of resonances are much larger than in similar $\mathrm{ZnO}$ devices. Also the Q factors are considerably higher. When the membrane is used as a piezoelectrically activated stator of a micro motor, voltages in the range of 1 to $3 \mathrm{~V}_{\text {rms }}$ are sufficient for its operation. This is 4 times less than was needed before with $\mathrm{ZnO}$ thin films. For equal amplitudes of the membrane, the voltages are reduced by a factor 4 to 10 ; for equal speeds by a factor 3 ; and for equivalent torques by a factor of 2 . The PZT thin film micromotor is able to work with standard supply voltages for IC 's delivered by single battery cells. 
Table 5: Effective amplitudes $A_{\text {eff }}$ per applied ac voltage obtained according to eqn. 9. $A_{\text {eff, } 0}$ is the minimal amplitude needed for motor operation. $A_{0}$ was deduced from the optical deflection measurements, taking into account the shape of the mode.

\begin{tabular}{|c|c|c|c|c|}
\hline & $\begin{array}{c}A_{\text {eff per Volt }} \\
(\mathrm{nm} / \text { Vrms })\end{array}$ & $\begin{array}{l}A_{\text {eff }}, 0 \\
(\mathrm{~nm})\end{array}$ & $\begin{array}{c}A_{0} \text { calculated } \\
(\mathrm{nm} / \mathrm{Vrms})\end{array}$ & $A_{\text {eff }} / A_{0}$ \\
\hline $21 \mathrm{kHz}, \mathrm{B}_{00}$, sputtered & $\begin{array}{c}20 \text { (no bias) } \\
23 \text { (-2V bias) }\end{array}$ & $\begin{array}{l}8 \\
7\end{array}$ & 57 & 0.35 \\
\hline $26 \mathrm{kHz}, \mathrm{B}_{00}$, sol gel & $\begin{array}{l}12 \text { (no bias) } \\
18 \text { (2V bias) }\end{array}$ & $\begin{array}{l}6 \\
6\end{array}$ & $\begin{array}{c}90 \\
120\end{array}$ & $\begin{array}{l}0.13 \\
0.15\end{array}$ \\
\hline $78 \mathrm{kHz}, \mathrm{B}_{10}$, sputtered & $\begin{array}{c}18 \text { (no bias) } \\
21 \text { (-2V bias) }\end{array}$ & $\begin{array}{c}9 \\
11\end{array}$ & 47 & 0.38 \\
\hline $94 \mathrm{kHz}, \mathrm{B}_{10}$, sol gel & $\begin{array}{l}37 \text { (no bias) } \\
47 \text { (2V bias) }\end{array}$ & $\begin{array}{l}21 \\
23\end{array}$ & $\begin{array}{c}75 \\
104\end{array}$ & $\begin{array}{l}0.49 \\
0.45\end{array}$ \\
\hline $\mathrm{ZnO}[5], 134 \mathrm{kHz}, \mathrm{B}_{10}$ & 4.4 & 9 & - & - \\
\hline
\end{tabular}

\section{Acknowledgement}

The research was supported by the Materials Priority Program of the Board of the Swiss Federal Institutes of Technology. Mr. Jacques Castano is acknowledged for technical assistance.

\section{References}

[1] A.M. Flynn, L.S. Tavrow, S.F. Bart, R.A. Brooks, D.J. Ehrlich, K.R. Udayakumar, and L.E. Cross, Piezoelectric micromotors for microrobots, J. Microelectromechanical Systems 1 (1992) 44-51.

[2] 2 R.M. Moroney, R.M White, and R.T. Howe, Ultrasonic micromotors: physics and applications, Proc. IEEEMEMS, Napa Valley, USA, 1990, pp. 182-187.

[3] 3 K.R. Udayakumar, S.F. Bart, A.M. Flynn, J. Chen, L.S. Tavrow, L.E. Cross, R.A. Brooks, and D.J. Ehrlich, Ferroelectric thin film ultrasonic micromotors, Proc. IEEE-MEMS, Nara, Japan, 1991, pp.109-113.

[4] 4 K.R. Udayakumar, J. Chen, A.M. Flynn, K.G. Brooks, L.E. Cross, and D.J. Ehrlich., Piezoelectric thin film ultrasonic micromotors, MRS Symposium Proceedings 243 (1992) 49-54 .

[5] 5 G.-A. Racine, R. Luthier, and N.F. de Rooj, Hybrid ultrasonic micromachined motors, Proc. IEEE-MEMS, Fort Lauderdale, USA, 1993, pp. 128-132.

[6] 6 K. Sreenivas, I. Reaney, T. Maeder, N. Setter, C. Jagadish, and R. G. Elliman, Investigation of Pt/Ti bilayer metallization on silicon for ferroelectric thin film integration, J.Appl.Phys 75 (1994) 232-239.

[7] 7 T. Uchiki, T. Nakazawa, K. Nakamura, M. Kurosawa, and S. Ueha, Ultrasonic motor utilizing elastic fin rotor, Jap.J.Appl.Phys. 30 (1991) 2289-2291.

[8] K.G. Brooks, I.A. Reaney, R. Klissurska, Y. Huang, L. Bursill, and N. Setter, Orientation of rapid thermally annealed lead zirconate titanate thin films on (111) Pt substrates, J. Mater. Res. 9 [10] (1994) 2540-2553.

[9] I. M. Reaney, K.G. Brooks, R. Klissurska, Cz. Pawlaczyk, and N. Setter, Use of transmission electron microscopy for the characterisation of rapid thermally annealed sol-gel PZT films, J.Amer.Ceram.Soc. 77 [5] (1994) 1209 - 1240.

[10] T. Maeder and P. Muralt, In-situ thin film growth of PbTiO3 by multi target sputtering, MRS Symposium Proceedings 341 (1994) 361-366.

[11] G.A. Racine, R. Luthier, P. Lugienbuhl, K. Brooks, N. Setter, and N.F. De Rooj, Hybrid ultrasonic elastic force motors micromachined in silicon, Intergrated Ferroelectrics, 8 (1995) 13-23.

[12] Istvan Szabo, Höhere Technische Mechanik, Springer, Berlin, 1956.

[13] Q.M. Zhang, W.Y. Pan, and L.E.Cross, J.Appl.Phys. 63 (1988) 2492-2496.

[14] Jie-Fang Li, D.D. Viehland, T. Tani, C.D.E. Lakeman, and D.A. Payne, Piezoelectric properties of sol-gelderived ferroelectric and antiferroelectric thin layers, J. Appl. Phys. 75 (1994) 442-448.

[15] M. Kurosawa, T. Uchiki, H. Hanada, K. Nakamura, and S. Ueha, Simulation and experimental study on elastic fin ultrasonic motor, IEEE Ultrasonics Symposium, Tucson, USA, 1992, pp. 893-896. 


\section{Biographies}

Paul Muralt was born in 1954. He received his diploma in physics and the Ph.D. degree for his investigations of incommensurate structural phase transitions from the Swiss Federal Institute of Technology in Zurich. In 1984 and 1985 he held a postdoctoral position at the IBM Research Laboratory in Zurich, working in the field of tunnelling microscopy and spectroscopy. Next, he started new activities in tunnelling microscopy at the Free University of Berlin. In 1987 he switched to industry, joining the Balzers group in Liechtenstein. Working in the business unit for semiconductor coating systems, he became a specialist in sputter-deposition techniques and managed a department for PVD process

development and application. In 1993 he returned to university and joined the laboratory of ceramic materials at the Swiss Federal Institute of Technology in Lausanne. His research interests are the deposition of ferroelectric thin films and the application of piezo- and pyroelectric thin films in micro sensors and actuators.

Markus Kohli was born in 1967. He studied physics at the Swiss Federal Institute of Technology in Zurich and received his diploma in 1993. He is now working on his Ph.D. thesis on the subject of materials and processing for micromechanics.

Thomas Maeder was born in 1970. He studied material sciences at the Swiss Federal Institute of Technology in Lausanne and received his diploma in 1992. He is now working on his Ph.D. thesis on fabrication and characterization of piezoelectric thin films.

Andrej Kholkin was born in 1954. He studied physics at the St. Petersburg State University and in 1988 received the Ph.D. at the Joffe Institute in St. Petersburg for his work in transport properties and kinetic phenomena in ferroelectrics. Afterwards, he continued at the same institute and extended his research to high- T, superconductors. In 1994 he joined the laboratory of ceramic materials at the Swiss Federal Institute of Technology in Lausanne. His research interests are now the characterization of piezoelectric thin films and membranes.

Keith G. Brooks was born in 1964. After his B.S. in ceramics engineering he received his Ph.D. in ceramics in 1990 at the New York State College of Ceramics at Alfred University. Later he worked as a research associate at the Materials Research Laboratory at Penn State University. In 1992 he joined the laboratory of ceramic materials at the Swiss Federal Institute of Technology in Lausanne. His current interests are chemical processing of advanced ceramics, including thin films for micromechanical applications.

Roland Luthier was born in 1960. After his studies in physics he wrote a thesis on thin-film growth and in 1990 received his Ph.D. from the Swiss Federal Institute of Technology in Lausanne. Afterwards he joined the sensor and actuator group at ASULAB, a research laboratory of the Swiss watch industry. His research interests are piezoelectric motors. 